\title{
Psychometric Properties of a Spanish Version of the Fear of COVID-19 Scale in General Population of Lima, Peru
}

\author{
Jeff Huarcaya-Victoria ${ }^{1}$ (D) David Villarreal-Zegarra ${ }^{2,3,4} \cdot$ Angela Podestà $^{5}$. \\ María Alejandra Luna-Cuadros ${ }^{6}$
}

Published online: 22 June 2020

C Springer Science+Business Media, LLC, part of Springer Nature 2020

\begin{abstract}
The current pandemic of the novel coronavirus COVID-19 has increased the anxiety and fear experienced by many. The main objective of this study was to analyze the psychometric properties of the Spanish-translated version of the Fear of COVID-19 Scale (FCV19S) using a sample of population in Peru. This is a cross-sectional instrumental study. Data were collected by a convenience sampling method, resulting in a total of 832 participants, and the collection took place over 1 week, April 17-23, 2020. The original version of the FCV-19S was translated from English into Spanish. The results support a bifactor model consisting of one general factor and two specific factors-one of emotional fear reactions and another of somatic expressions of fear of COVID-19 (CFI= 0.988 , RMSEA = 0.075). Invariance between healthcare workers and age groups was reached $(\triangle \mathrm{CFI}<0.01)$, but the invariance between men and women was not met $(\Delta \mathrm{CFI}=0.02)$. Convergent validity was found with depressive, anxious, and posttraumatic stress symptoms. The general factor of the fear of COVID-19 and two specific factors had an optimal level of internal consistency $(\omega>0.89$ and $\alpha>0.83)$. The study found the Spanish-translated version of the FCV-19S has good psychometric properties and presents evidence of validity and reliability.
\end{abstract}

Keywords COVID-19 $\cdot$ Fear $\cdot$ Peru $\cdot$ Psychometrics $\cdot$ Bifactor $\cdot$ Fear of COVID-19 scale

\section{Background}

The current pandemic of the new coronavirus COVID-19 (SARS-CoV-2; coronavirus disease 2019) has spread to many countries. On January 30, 2020, the Emergency Committee of the

Electronic supplementary material The online version of this article (https://doi.org/10.1007/s11469-02000354-5) contains supplementary material, which is available to authorized users.

David Villarreal-Zegarra

davidvillarreal@ipops.pe

Extended author information available on the last page of the article 
World Health Organization (WHO) designated this outbreak a global health emergency based on the increasing case notification rates in China and other countries (Velavan and Meyer 2020). In Peru, as of June 3, 2020, there have been 178914 confirmed cases; 4894 reported deaths; and the mortality rate was $2.74 \%$ (Gobierno del Perú 2020). One psychological aspect of the COVID-19 pandemic is fear, which is defined as an unpleasant emotional state that is triggered by the perception of threatening stimuli (Pakpour and Griffiths 2020). The relationship between infectious disease and fear is directly related to its form of transmission (rapid and invisible) and mortality rate (Ahorsu et al. 2020). Due to the high communicability of COVID-19 and the increasing number of confirmed cases and deaths worldwide, negative emotions and thoughts have become more frequent (Duan and Zhu 2020). Negative behaviors in society are often driven by fear. This fear experience can evolve into a range of mental health problems, including distress reactions (insomnia, anger, irritability), health risk behaviors (increased alcohol and tobacco use), and mental disorders (posttraumatic stress disorder, anxiety, and depression disorders), among others (Shigemura et al. 2020). The proliferation of fear generates erratic behaviors among people during infectious outbreaks, which is an expected phenomenon (Ho et al. 2020). Health professionals must provide timely and sufficient attention to feelings of fear in the general population. To achieve this, it is necessary to have adequate instruments to assess the fear caused by COVID-19.

The Fear of COVID-19 Scale (FCV-19S) was developed to assess this fear in the general population in Iran and showed adequate psychometric properties. This scale has been validated in Italian (Soraci et al. 2020), Arabic (Alyami et al. 2020), Bangla (Sakib et al. 2020), and Turkish (Satici et al. 2020). However, there is no validation of this scale in the Spanish language which limits the possibility of cross-cultural research. Also, recent studies have demonstrated that two-dimensional models could better explain the structure of the FCV-19S (Reznik et al. 2020; Tzur Bitan et al. 2020), so analyses of the internal structure of the FCV$19 \mathrm{~S}$ must be carried out to determine whether a one-dimensional model or two-dimensional model is most suitable.

Although different studies have been carried out on the FCV-19S, evidence on the measurement invariance of this scale has not been assessed. Invariance is a very important measurement property since it allows comparisons to be made between groups (Putnick and Bornstein 2016). If the invariance is satisfied, the amount of fear between men and women or between healthcare workers and the general population may be compared.

The main goal of this study was to evaluate the psychometric properties of the Spanishtranslated version of the FCV-19S using a sample of the general population of Lima, Peru. Our study evaluates different indicia of validity such as internal structure, invariance of measurement, and relationship with other variables (convergent validity). Reliability is also evaluated through internal consistency coefficients.

\section{Methods}

\section{Study Design and Target Population}

This is a cross-sectional investigation. The study population was the general population of Lima, Peru. A convenience sampling strategy was utilized. Following the social distance recommendation, participants were recruited from online advertisements, e-mail, and social media. Data collection took place over 1 week, April 17-23, 2020, 1 month after the state of 
emergency was declared and mandatory self-quarantine was ordered in Peru. Inclusion criteria included: 18 to 80 years of age and an agreement to participate in the online survey.

\section{Measurement Instruments}

\section{Fear of COVID-19 Scale}

The FCV-19S is a novel, seven-item unidimensional scale with good psychometric properties used in assessing fears of COVID-19 among the general population. All items are rated on a 5point scale, ranging from 1 (strongly disagree) to 5 (strongly agree). Total scores range from 7 to 35. The higher the score, the greater the fear of COVID-19 (Ahorsu et al. 2020). The items of the FCV-19S were constructed based on an extensive review of existing fear scales, and it shows an acceptable item-total correlation. Reliability values such as internal consistency (Cronbach's alpha $=0.82$ ) and test-retest reliability (intraclass correlation coefficient $=0.72$ ) were acceptable. Concurrent validity was supported by the Hospital Anxiety and Depression Scale (HADS) (depression, $r=0.425$, and anxiety, $r=0.511$ ) and the Perceived Vulnerability to Disease Scale (PVDS) (perceived infectability, $r=0.483$, and germ aversion, $r=0.459$ ) (Ahorsu et al. 2020). In this study, the original version of the FCV-19S was translated from English to Spanish by one author with clinical and research experience (A. Podestà). Subsequently, the authors discussed the nuanced meanings of the translation and agreed on a final Spanish version of this scale. The translated Spanish version of the FCV-19S was then forwarded to one bilingual (English/Spanish) independent professional for review.

\section{Posttraumatic Stress}

To assess levels of distress, the self-reporting Impact of Event Scale-Revised (IES-R), where each of the 22 items are rated on a Likert scale ranging from 0 (not at all) to 4 (extremely), was used (Weiss and Marmar 1997). In the present study, the IES-R had adequate internal consistency (Cronbach's alpha $=0.964)$.

The IES-R has three sub-dimensions. The first sub-dimension is Intrusion. It is composed of eight items (items 1, 2, 3, 6, 9, 14, 16, and 20), and evaluates indicators of intrusive thoughts, nightmares, intrusive feelings and imagery, and dissociative-like re-experiencing. The second sub-dimension, Avoidance, consists of eight items (items 5, 7, 8, 11, 12, 13, 17, 22) which are used to assess indicators of numbed responsiveness and avoidance of feelings, situations, and ideas. The third sub-dimension is Hyperarousal. Composed of six items (items $4,10,15,18,19,21)$, it looks at indicators of anger, irritability, hypervigilance, difficulty concentrating, and heightened startle response.

\section{Depressive Symptoms}

For the evaluation of depressive symptoms, the Patient Health Questionnaire-9 (PHQ-9) was used. The PHQ-9 is also a self-administered scale consisting of nine items rated on a Likert scale ranging from 0 (not at all) to 3 (almost every day). In studies carried out in Latin America, the PHQ-9 has been proven to be a valid and reliable tool for detecting depressive symptoms in various populations (Cassiani-Miranda et al. 2017; Saldivia et al. 2019). The PHQ-9 was validated in Peru. Indicia of validity include internal structure, invariance of measurement, and adequate values of internal consistency 
(Villarreal-Zegarra et al. 2019). The present study confirmed adequate internal consistency $($ Cronbach's alpha $=0.877)$.

\section{Anxious Symptoms}

Generalized Anxiety Disorder-7 (GAD-7) is a valid and efficient self-administered scale to assess the severity of anxiety disorders in clinical practice (Spitzer et al. 2006). The scale has been previously translated into Spanish and validated (Garcia-Campayo et al. 2010). It consists of seven items designed to measure anxiety symptomatology during the 2 weeks before selfapplication. Each item is rated on a Likert scale ranging from 0 (not at all) to 3 (almost every day). In the present study, the GAD-7 had adequate internal consistency (Cronbach's alpha= 0.898).

\section{Data Analysis}

\section{Characteristics of Participants}

A descriptive analysis of participant characteristics was conducted. Frequencies, percentages, and measures of central tendency and dispersion were used with average item scores.

\section{Factorial Analysis}

Two types of factor analyses were performed; the first, to explore how the items relate to each other (exploratory factor analysis), and the second, to confirm different theoretically valid models of the FCV-19S (confirmatory factor analysis). To perform these analyses on the same group, the sample was split into two random groups corresponding to half of the sample in each group (split-half method) (Anderson and Gerbing 1988; Lloret-Segura et al. 2014). With one half of participants, the relationship of the items can be explored, and with the other half of participants, the results can be confirmed.

The exploratory factor analysis used the robust maximum likelihood estimator (MLR) (Brown 2015), the Pearson matrices, and oblique rotation (quartimin). The parallel analysis test was used to determine the most appropriate number of dimensions (Timmerman and Lorenzo-Seva 2011). Since different research and theoretical models on fear suggest that it is a multidimensional construct, different factorial solutions were evaluated; dimensions confirmed by a minimum of three items were deemed stable (Muñiz 2018).

Confirmatory factor analysis (CFA) was performed using MLR and Pearson matrices. The models evaluated in the confirmatory analysis were those produced by exploratory factorial analysis and those generated by possible higher entities (bifactorial and second-order models).

The evaluation of the different models was done in three steps. First, different goodness-offit indices (GFIs) were evaluated. The comparative fit index (CFI) and the Tucker-Lewis Index (TLI), both with appropriate values $\geq 0.90$; the Standardized Root Mean Square Residual (SRMR); and the Root Mean Square Error of Approximation (RMSEA), with a confidence interval of $90 \%$, and with adequate values $<0.08$, were used to compare model fit (Brown 2015; Hu and Bentler 1998). Using the Akaike information criterion (AIC) and the Bayesian information criterion (BIC), models with the lowest values were interpreted as having the best fit. 
Second, for multidimensional models, to ensure that dimensions are different constructs, the dimensions are expected to have a moderate or low latent correlations between them. If the ratio is very high $(>0.80)$, it suggests the dimensions are overlapping and cannot be clearly differentiated (Brown 2015).

Third, in the bifactorial models, the relevance of the general (bifactorial) factor and the specific factors was evaluated. The hierarchical omega indices $(\omega \mathrm{Hs})$, percentage of uncontaminated correlations (PUCs), and explained common variance (ECV) were used. It was considered a good fit when $\omega H$ had a value $\geq 0.70$ in the general factor and a value $\geq 0.30$ in the specific factors, a PUC $\geq 0.70$, and a ECV $\geq 0.70$ (Dominguez-Lara and Rodriguez 2017; Rodriguez et al. 2016).

The use of models with correlated errors was avoided because they involve the assumption of hypotheses that are not always possible to test, and these models can artificially inflate goodness-of-fit indices (DeShon 1998).

\section{Measurement Invariance}

Multiple models of the CFA measurement invariance were evaluated through groups defined by relevant variables-e.g., sex, age, healthcare work. Four measurement models with progressive restrictions were compared between categories within these groupse.g., between people aged 18 to 39 and people over 40 (Putnick and Bornstein 2016; Widaman and Reise 1997). If two or more groups reach invariance, it is assumed that comparisons can be made between these groups (Putnick and Bornstein 2016). The change in the CFI $(\triangle \mathrm{CFI})$ was used as the principal criterion to compare the models with more restrictions with the models with fewer restrictions. A $\Delta$ CFI of $<0.01$ was used as a cutoff point (Putnick and Bornstein 2016). The $\Delta$ CFI criterion was preferred over $\chi^{2}$ comparisons since the former is not sensitive to large sample sizes (Putnick and Bornstein 2016; Widaman and Reise 1997).

\section{Convergent Validity}

Convergent validity was evaluated using correlation analyses between the FCV-19S and the PHQ-9, GAD-7, and IES-R scales. FCV-19S was expected to be moderately or strongly related to the other scales. This correlation was determined by Spearman's rho $\left(r_{\mathrm{s}}\right)$ since the normality assumptions were not fulfilled. A large $\left(r_{\mathrm{s}}>0.70\right)$, moderate $\left(r_{\mathrm{s}}>\right.$ $0.50)$, or small $\left(r_{\mathrm{s}}>0.30\right)$ ratio is determined based on the size of the correlation coefficient.

\section{Reliability}

Reliability was evaluated using two internal consistency coefficients ( $\alpha$ and $\omega$ ). Both are acceptably reliable when the coefficients have values greater than 0.80 (Kelley and Pornprasertmanit 2016; McDonald 1999).

\section{Software}

All analyses were done in RStudio, with the lavaan, semTools, GPArotation, BifactorIndicesCalculator, and semPlot packages. 


\section{Results}

\section{Characteristics of Participants}

A total of 832 participants were included in the study. Initially, 838 participants were evaluated, but those who did not meet the inclusion criteria-i.e., did not agree to participate $(n=2)$, were better off $(n=2)$, or were over 80 years old $(n=2)$-were eliminated. The participants' mean age was 38.37 years $(\mathrm{SD} \pm 12.75)$. The majority of participants were female $(65.6 \%)$, single (49.0\%), with university education (76.4\%), and formal employment $(66.9 \%)$. The detailed sociodemographic features can be found in Table 1 .

\section{Exploratory Factor Analyses}

In the two-factor model, the first factor has items of emotional fear reactions (F1) and the second factor has items of somatic expressions of fear of COVID-19 (F2). Exploratory factor analyses determined that the factor loads for the one-factor model and the two-factor model were adequate $(\lambda>0.49)$ (see Table 2$)$. In the case of the two-factor model, the correlation between its factors was 0.72 . The parallel analysis suggests a two-dimensional model.

Table 1 Sociodemographic characteristics of the study population $(n=832)$

\begin{tabular}{|c|c|c|c|}
\hline & & $n$ & $\%$ \\
\hline \multirow[t]{6}{*}{ Age } & 18 to 19 & 20 & 2.4 \\
\hline & 20 to 29 & 220 & 26.4 \\
\hline & 30 to 39 & 275 & 33.1 \\
\hline & 40 to 49 & 135 & 16.2 \\
\hline & 50 to 59 & 111 & 13.3 \\
\hline & 60 and up & 71 & 8.5 \\
\hline \multirow[t]{2}{*}{ Sex } & Men & 286 & 34.4 \\
\hline & Women & 546 & 65.6 \\
\hline \multirow[t]{4}{*}{ Civil status } & Married & 345 & 41.5 \\
\hline & Divorced & 71 & 8.5 \\
\hline & Single & 408 & 49.0 \\
\hline & Widowed & 8 & 1.0 \\
\hline \multirow[t]{4}{*}{ Educational level } & Primary & 1 & 0.1 \\
\hline & Secondary & 83 & 10.0 \\
\hline & Technical & 112 & 13.5 \\
\hline & University & 636 & 76.4 \\
\hline \multirow[t]{3}{*}{ Labor status } & Formal employment & 557 & 66.9 \\
\hline & Informal employment & 96 & 11.5 \\
\hline & Unemployed & 179 & 21.5 \\
\hline \multirow[t]{2}{*}{ Do you have a religion? } & No & 258 & 31.0 \\
\hline & Yes & 574 & 69.0 \\
\hline \multirow[t]{2}{*}{ Diagnosis of a mental health problem? } & No & 716 & 86.1 \\
\hline & Yes & 116 & 13.9 \\
\hline \multirow[t]{2}{*}{ Healthcare worker? } & No & 640 & 76.9 \\
\hline & Yes & 192 & 23.1 \\
\hline \multirow[t]{5}{*}{ Number of inseparable symptoms of COVID* } & None & 569 & 68.4 \\
\hline & 1 & 175 & 21.0 \\
\hline & 2 & 54 & 6.5 \\
\hline & 3 & 29 & 3.5 \\
\hline & 4 or more & 5 & 0.6 \\
\hline
\end{tabular}

*Cough, fatigue, muscle pain, headache, or diarrhea 
Table 2 Factor loads of exploratory factor analysis with the one-factor model and two-factor model $(n=416)$

\begin{tabular}{llllll}
\hline & One-factor model & \multicolumn{2}{l}{ Two-factor model } & & \\
\cline { 5 - 6 } & $\lambda \mathrm{F} 1$ & $\lambda \mathrm{F} 1$ & $\lambda \mathrm{F} 2$ & $\mathrm{M}$ & $\mathrm{SD}$ \\
\hline Item 1 & 0.711 & 0.933 & - & 2.9 & 1.3 \\
Item 2 & 0.677 & 0.686 & - & 2.7 & 1.2 \\
Item 3 & 0.595 & - & 0.672 & 1.6 & 0.9 \\
Item 4 & 0.744 & 0.656 & - & 2.5 & 1.3 \\
Item 5 & 0.778 & 0.489 & - & 2.5 & 1.3 \\
Item 6 & 0.720 & - & 0.860 & 1.8 & 1.0 \\
Item 7 & 0.766 & - & 0.824 & 1.8 & 1.0 \\
\hline
\end{tabular}

$\lambda=$ factor loads. $F 1=$ first factor. $F 2=$ second factor. $M=$ mean. $S D=$ standard deviation

\section{Confirmatory Factor Analyses}

The one-factor model, two-factor model, and second-order model with two-factor of first-order have an inadequate level of RMSEA ( $>0.08$ ). The bifactor model was adequate in all fit indices (CFI and TLI > 0.90 and RMSEA and SRMR < 0.08) (see Table 3). Analysis of the bifactor model shows that the explained common variance $(\mathrm{ECV}=0.725)$ is adequate, but the percentage of uncontaminated correlations are low ( $\mathrm{PUC}=0.571)$. The $\omega \mathrm{H}$ is adequate in the general factor but low in the specific factors (see Fig. 1). Moreover, item 5 contributes very little to emotional fear reactions (F1).

\section{Invariance}

The bifactor model with two specific factors is invariant between healthcare workers and nonhealthcare workers and between people who are under 40 years of age and those who are over 40 years of age $(\Delta \mathrm{CFI}<0.01)$ (see Table 4$)$. Therefore, comparisons can be made between these groups. However, invariance is not met between men and women. Therefore, comparisons between these groups cannot be made, and future analyses should be carried out in a stratified manner by sex.

Table 3 Confirmatory factor analysis rates for the one-factor model, two-factor model, second-order model, and bifactor model $(n=416)$

\begin{tabular}{llllllllll}
\hline & $\chi^{2}$ & df & CFI & TLI & RMSEA [90\% CI $]$ & SRMR & AIC & BIC \\
\hline Spanish (our study) & & & & & & & & \\
$\quad$ One-factor model & 362.44 & 14 & 0.825 & 0.738 & $0.173[0.160-0.186]$ & 0.080 & $15,459.1$ & $15,525.2$ \\
$\quad$ Two-factor model & 117.61 & 13 & 0.947 & 0.915 & $0.098[0.084-0.113]$ & 0.044 & $15,101.5$ & $15,172.3$ \\
Second-order model & 108.57 & 12 & 0.952 & 0.915 & $0.098[0.084-0.113]$ & 0.044 & $15,103.5$ & $15,179.1$ \\
$\quad$ Bifactor model & 39.85 & 7 & 0.988 & 0.964 & $0.075[0.054-0.098]$ & 0.022 & $15,008.8$ & $15,108.0$ \\
Arabic (one-factor model) & & & & & & & & & \\
$\quad$ One-factor model & - & - & 0.957 & - & $0.152[0.135-0.170]$ & 0.066 & & \\
$\quad$ One-factor model* & - & - & 0.991 & - & $0.081[0.061-0.102]$ & 0.035 & & \\
$\quad$ One-factor model** & - & - & 0.995 & - & $0.059[0.037-0.083]$ & 0.024 & & \\
Turkish (one-factor model) & 299.47 & 13 & 0.915 & - & - & & 0.061 & & \\
Bangla (one-factor model) & 554.75 & 14 & 0.964 & 0.947 & 0.071 & & & \\
Italian (one-factor model)*** & 26.07 & 12 & 0.99 & 0.99 & $0.069[0.032-0.105]$ & 0.047 & & \\
\hline
\end{tabular}

$\chi^{2}=$ chi-square. $d f=$ degree of freedom. $C F I=$ comparative fit index. $T L I=$ Tucker-Lewis Index. $R M S E A=\operatorname{root}$ mean square error of approximation. $S R M R=$ standardized root mean square

*Errors 3, 6, 7 correlated

**Errors 3, 6, 7, 1, 2 correlated

***Errors 1, 5, 2, 7 correlated 


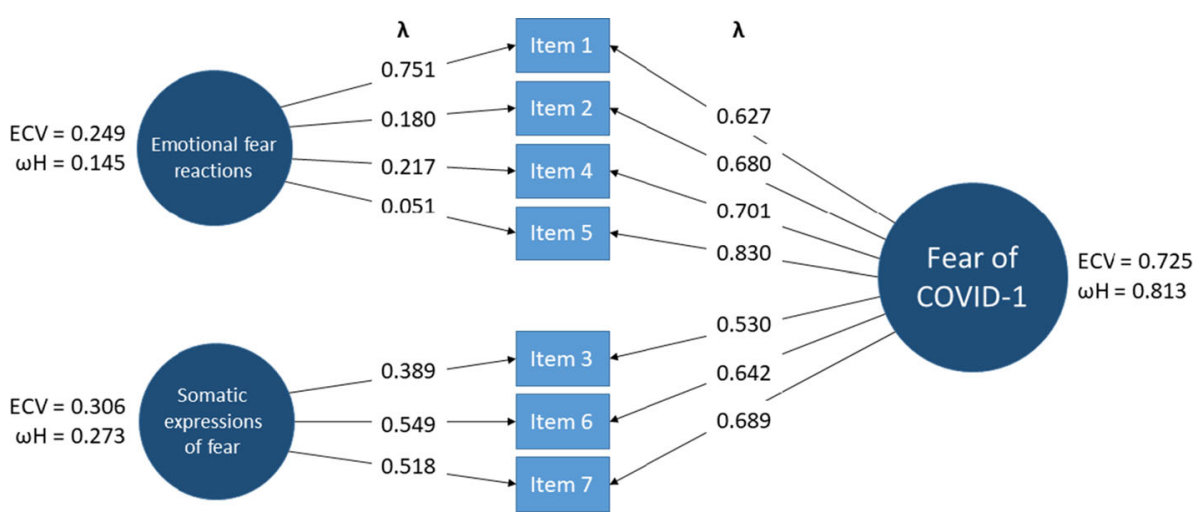

Note: $\lambda=$ factorial loads, $\mathrm{ECV}=$ explained common variance, $\omega \mathrm{H}=$ hierarchical omega

Fig. 1 Factorial loads and fit rates of the bifactor model $(n=416) . \lambda=$ factorial loads, ECV $=$ explained common variance, $\omega \mathrm{H}=$ hierarchical omega

\section{Convergent Validity}

The general factor as well as the specific factors (F1 and F2) present a moderate correlation with the variables related to posttraumatic stress $(r>0.5)$, and the relationship of these dimensions is greater in comparison to depressive and anxious symptoms. Men have a lower correlation coefficient compared to women (see Fig. 2). The correlation coefficients of the overall value (men and women combined) are found in Supplement 1.

\section{Reliability}

The general factor of the FCV-19S $(\omega=0.94, \alpha=0.88,7$ items $)$, the specific factor of emotional fear reactions (F1) ( $\omega=0.91, \alpha=0.85,4$ items), and the specific factor of somatic

Table 4 Invariance analysis of the Fear of COVID-19 Scale $(n=832)$

\begin{tabular}{|c|c|c|c|c|c|c|c|c|c|c|}
\hline & \multirow[b]{2}{*}{ Invariance } & \multicolumn{3}{|c|}{$\begin{array}{l}\text { Robust } \chi^{2} \text { goodness-of- } \\
\text { fit }\end{array}$} & \multirow[b]{2}{*}{ CFI } & \multirow[b]{2}{*}{ RMSEA } & \multirow[b]{2}{*}{$\Delta \mathrm{CFI}$} & \multicolumn{3}{|c|}{ DIFFTEST } \\
\hline & & Value & $d f$ & $p$ & & & & Value & $d f$ & $p$ \\
\hline \multirow{3}{*}{$\begin{array}{l}\text { Sex } \\
\text { (men vs women) }\end{array}$} & Configural & 47.8 & 14 & $<0.001$ & 0.989 & 0.076 & - & - & - & - \\
\hline & Metric & 68.1 & 25 & $<0.001$ & 0.985 & 0.064 & -0.003 & 20.3 & 11 & 0.041 \\
\hline & Strong & 145.6 & 32 & $<0.001$ & 0.962 & 0.092 & -0.024 & 77.5 & 7 & $<0.001$ \\
\hline \multirow{3}{*}{$\begin{array}{l}\text { Healthcare worker } \\
\text { (yes vs no) }\end{array}$} & Configural & 54.7 & 14 & $<0.001$ & 0.986 & 0.084 & - & - & - & - \\
\hline & Metric & 64.6 & 25 & $<0.001$ & 0.987 & 0.062 & 0 & 9.9 & 11 & 0.539 \\
\hline & Strong & 78.9 & 32 & $<0.001$ & 0.984 & 0.059 & -0.002 & 14.4 & 7 & 0.045 \\
\hline \multirow{3}{*}{$\begin{array}{l}\text { Age } \\
\text { (18-39 vs } 40 \text { and up) }\end{array}$} & Configural & 54.5 & 14 & $<0.001$ & 0.986 & 0.083 & - & - & - & - \\
\hline & Metric & 65.2 & 25 & $<0.001$ & 0.986 & 0.062 & 0 & 10.7 & 11 & 0.471 \\
\hline & Strong & 78.8 & 32 & $<0.001$ & 0.986 & 0.055 & 0 & 7.6 & 7 & 0.364 \\
\hline
\end{tabular}

$d f=$ degrees of freedom; $C F I=$ comparative fit index; $R M S E A=$ root mean square error of approximation; $\triangle C F I=$ variation of the comparative fit index; DIFFTEST $=$ ANOVA difference test 


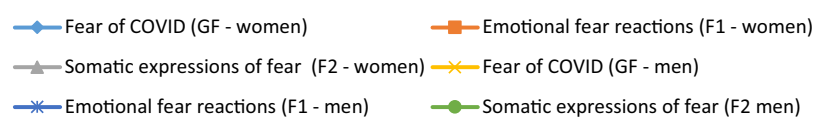

0.6

0.5

0.4

0.3

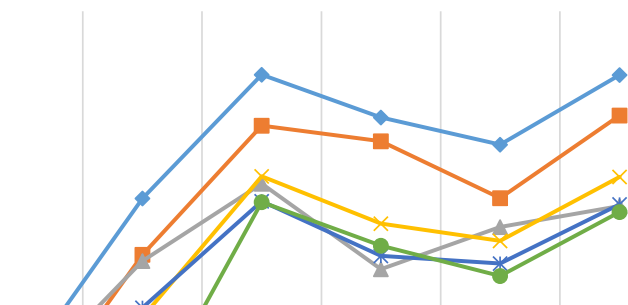

0.2

0.1

\begin{tabular}{|c|c|c|c|c|c|}
\hline $\begin{array}{c}\text { Depressive } \\
\text { symptoms }\end{array}$ & $\begin{array}{c}\text { Anxious } \\
\text { symptoms }\end{array}$ & PTS Intrusion & $\begin{array}{c}\text { PTS } \\
\text { Avoidance }\end{array}$ & $\begin{array}{c}\text { PTS } \\
\text { Hyperarousal }\end{array}$ & $\begin{array}{c}\text { Post- } \\
\text { traumatic } \\
\text { Stress (Total) }\end{array}$ \\
\hline 0.3269 & 0.4563 & 0.5513 & 0.5186 & 0.4977 & 0.5512 \\
\hline 0.2844 & 0.4129 & 0.5122 & 0.5003 & 0.4564 & 0.52 \\
\hline 0.3136 & 0.4081 & 0.4676 & 0.4019 & 0.4342 & 0.4504 \\
\hline 0.2548 & 0.3649 & 0.4732 & 0.4369 & 0.4237 & 0.4728 \\
\hline 0.2606 & 0.3723 & 0.4541 & 0.4121 & 0.4063 & 0.4517 \\
\hline 0.2133 & 0.287 & 0.4534 & 0.4199 & 0.3967 & 0.4459 \\
\hline
\end{tabular}

Note: $\mathrm{GF}=$ General factor. F1 $=$ First factor. F2 $=$ Second factor. PTS $=$ Posttraumatic Stress.

Fig. 2 Correlation between Fear of COVID-19 Scale dimensions and depressive symptoms, anxiety symptoms, and posttraumatic stress by sex $(n=832)$. GF $=$ general factor. $\mathrm{F} 1=$ first factor. $\mathrm{F} 2=$ second factor. $\mathrm{PTS}=$ posttraumatic stress

expressions of fear (F2) ( $\omega=0.89, \alpha=0.83,3$ items) have an optimal level of internal consistency. The corrected total item correlation was high in all cases $\left(r_{\text {cit }}>0.50\right)$, and the values of internal consistency between men and women were the same.

\section{Discussion}

\section{Main Findings}

The results of the present study indicate that the Spanish version of the FCV-19S has good psychometric properties and presents evidence of validity and reliability. Therefore, its use is recommended in different contexts. 
The results of this study support a general factor, composed of seven items, and two specific factors: emotional fear reactions, composed of four items, and somatic expressions of fear of COVID-19, composed of three items. Comparisons can be made between healthcare workers and the general population, as well as between different age groups. However, as demonstrated by the failure to satisfy measurement invariance, men and women have different perceptions and fear of COVID-19, so analyses should be stratified by sex.

\section{Factorial Structure}

The results of the CFA in this study suggest the use of a bifactor model for scale analyses (the general factor and the specific somatic and emotional factors). This differs from the analyses reported in the scale creation study reporting that the FCV-19S has a stable one-dimensional structure (Ahorsu et al. 2020; Sakib et al. 2020). The first factor includes different concerns caused by an emotional specific factor related to COVID-19. The second specific factor includes somatic components (sweating, palpitations, insomnia). Because there is a logical association between psychological and somatic manifestations, assessment of these two specific factors makes sense. The findings of this study support the idea that fear of COVID-19 is a multidimensional construct; therefore, it is useful to employ an overall scale score for the general factor and separate scores for each specific factor.

It is noteworthy that the Arabic, Turkish, and Bangla versions do not report the same GFIs. In general, the two-factor model of the Spanish version of the FCV-19S reports similar adjustments of the CFI, TLI, and SRMR indices compared to the other univariate versions of the FCV-19S. However, the RMSEA did not adequately adjust; the analyses in this study identified measurement problems in the one-dimensional models and in the two-dimensional models of the scale based on a very high RMSEA in the one-dimensional version. This problem has been recorded in another study (Alyami et al. 2020). Attempts to fix this by using correlated errors may be artificially inflating the GFIs. The use of the bifactor model provides a simpler factorial solution with optimal GFIs; this overcomes the limitations identified in previous studies which presented a very high RMSEAs.

\section{Invariance}

Studies evaluating the importance of factor invariance of the FCV-19S were not found, so this is the first study that affirms the ability to make comparisons between groups using this scale. The results of this study indicate that men and women understand the construct of fear of COVID-19 differently and therefore are not invariant. This may be because women experience a higher prevalence of fear-based emotional problems compared to men (Villarreal-Zegarra and Bernabe-Ortiz 2020). Therefore, subsequent research incorporating the FCV-19S should include analyses stratified by sex. It should be noted that other psychometric study assessment instruments for emotional problems have also observed that sex is not invariant. For example, the PHQ-9, a study using a Brief Depressive Symptom Scale, found that men and women had dissimilar understandings of the same construct and invariance was not achieved (Baas et al. 2011). However, there is some contradictory evidence; several studies have found invariance between the sexes for emotional problems such as depressive symptoms using the PHQ-9 (Gonzalez-Blanch et al. 2018; Keum et al. 2018; Villarreal-Zegarra et al. 2019).

As the results of this study did confirm that comparisons can be fairly made between healthcare workers and non-healthcare workers and between different age groups, it is recommended that future users of the scale focus on these analyses. 


\section{Convergent Validity}

The correlations with PHQ-9, GAD-7, and IES-R suggest that the Spanish version of the FCV19S has adequate convergent validity. Furthermore, this suggests that people with severe fear of COVID-19 have concurrently higher levels of anxiety, depression, and distress. These results are similar to those reported by Ahorsu et al., who found that FCV-19S correlated with depression and anxiety (as measured with HADS) and perceived infectivity and aversion to germs (as measured with PVDS) (Ahorsu et al. 2020). In a study using the Arabic version, an association was also reported between the FCV-19S and levels of anxiety and depression measured through HADS (Alyami et al. 2020). Fear can generate negative behaviors in the society, and those experiences can evolve to include a range of public mental health problems - e.g., depression, anxiety, distress, and others (Shigemura et al. 2020).

\section{Reliability}

The internal consistency of the Spanish FCV-19S was 0.87 , which is similar to the 0.82 reported for the original scale (Ahorsu et al. 2020), 0.88 for the Arabic version (Alyami et al. 2020), 0.85 for the Turkish (Satici et al. 2020), 0.87 for the Bangla version (Sakib et al. 2020), 0.81 for the Russian version (Reznik et al. 2020), 0.86 for the Hebrew version (Tzur Bitan et al. 2020), and 0.87 for the Italian version (Soraci et al. 2020). From the consistency across the versions, it can be inferred that the FCV-19S measurements are inherently stable.

\section{Public Health Relevance}

Extraordinary events such as pandemics can induce fear across a population, generating various mental health problems. Fear of COVID-19 is likely due to its novelty and uncertainties about the severity of the threats it poses. The immediate priority is the collection of high-quality data on the mental health and psychological effects of the COVID-19 pandemic across the general population and in specifically vulnerable groups (e.g., healthcare workers, people with physical symptoms, the unemployed population) (Holmes et al. 2020; Wang et al. 2020). Thus, the FCV-19S could help us find people with the greatest psychological vulnerabilities, such as intolerance to uncertainty and perceived vulnerability to illness (Asmundson and Taylor 2020). Without an understanding of the fear evoked by COVID-19 among the different sociodemographic groups, it will be difficult to know what prevention and education programs are useful and necessary (Pakpour and Griffiths 2020). With a correct base of understanding, fears can be effectively addressed through the dissemination of relevant information through various media (Chung-Ying 2020).

\section{Strengths and Limitations}

Due to limited resources and the need to quickly generate information on the mental health effects of this pandemic, a convenience sampling strategy was employed; as a result, the findings may not be representative of the general population. Furthermore, as most of the sample consisted of participants with university educations and with a formal employment, the results should not be generalized. Future research should assess the measurement invariance of the Spanish version of the FCV-19S among participants with less education, who are unemployed or employed in informal jobs or unemployed jobs, and who are without Internet access. This study did not 
include formal diagnoses of mood problems, so sensitivity and specificity could not be addressed but should be considered in future research. Finally, as a cross-sectional study, the stability of the FCV-19S over time was not evaluated, and future longitudinal studies are required. Despite these limitations, this study provides valuable information on the usefulness of Spanish translation of the FCV-19S and its application within the Peruvian population.

\section{Conclusions}

In summary, this study shows that the Spanish version of the FCV-19S when administered to a limited population of Lima, Peru, demonstrated a bifactor model with adequate psychometric properties. Therefore, it is recommended to use it within the general population.

\section{Compliance with Ethical Standards}

Conflict of Interest The authors declare that they have no conflict of interest.

Ethical Approval All procedures performed in this study involving human participants conducted according to the ethical standards of the research team's organizational Ethics Board and the 1975 Helsinki Declaration.

Informed Consent Informed consent was obtained from all participants.

\section{Appendix. Spanish Version of the Fear of COVID-19 Scale}

1. Tengo mucho miedo del coronavirus (COVID-19)

2. Me pone incómodo(a) pensar en el coronavirus (COVID-19)

3. Mis manos se ponen húmedas cuando pienso en el coronavirus (COVID-19)

4. Tengo miedo de perder mi vida a causa del coronavirus (COVID-19)

5. Cuando veo noticias e historias sobre el coronavirus (COVID-19) en redes sociales me pongo nervioso(a) o ansioso(a)

6. No puedo dormir porque estoy preocupado de contagiarme del coronavirus (COVID-19)

7. Mi corazón se acelera o palpita cuando pienso en contagiarme del coronavirus (COVID-19)

\section{References}

Ahorsu, D. K., Lin, C. Y., Imani, V., Saffari, M., Griffiths, M. D., \& Pakpour, A. H. (2020). The Fear of COVID19 Scale: development and initial validation. International Journal of Mental Health and Addiction, 1-9. https://doi.org/10.1007/s11469-020-00270-8.

Alyami, M., Henning, M., Krägeloh, C. U., \& Alyami, H. (2020). Psychometric evaluation of the Arabic version of the Fear of COVID-19 Scale. International Journal of Mental Health and Addiction. https://oi. org/10.1007/s11469-020-00316-x.

Anderson, J. C., \& Gerbing, D. W. (1988). Structural equation modeling in practice: a review and recommended two-step approach. Psychological Bulletin, 103(3), 411-423. https://doi.org/10.1037/0033-2909.103.3.411.

Asmundson, G. J. G., \& Taylor, S. (2020). Coronaphobia: fear and the 2019-nCoV outbreak. Journal of Anxiety Disorders, 70, 102196. https://doi.org/10.1016/j.janxdis.2020.102196. 
Baas, K. D., Cramer, A. O., Koeter, M. W., van de Lisdonk, E. H., van Weert, H. C., \& Schene, A. H. (2011). Measurement invariance with respect to ethnicity of the Patient Health Questionnaire-9 (PHQ-9). Journal of Affective Disorders, 129(1-3), 229-235. https://doi.org/10.1016/j.jad.2010.08.026.

Brown, T. A. (2015). Confirmatory factor analysis for applied research (Second ed.). New York: The Guilford Press.

Cassiani-Miranda, C. A., Vargas-Hernández, M. C., Pérez-Aníbal, E., Herazo-Bustos, M. I., \& HernándezCarrillo, M. (2017). Confiabilidad y dimensión del cuestionario de salud del paciente (PHQ-9) para la detección de síntomas de depresión en estudiantes de ciencias de la salud en Cartagena, 2014. Biomédica, 37(Supl. 1), 112-120.

Chung-Ying, L. (2020). Social reaction toward the 2019 novel coronavirus (COVID-19). Social Health and Behavior, 3(1), 1.

DeShon, R. P. (1998). A cautionary note on measurement error corrections in structural equation models. Psychological Methods, 3(4), 412-423. https://doi.org/10.1037/1082-989X.3.4.412.

Dominguez-Lara, S., \& Rodriguez, A. (2017). Índices estadísticos de modelos bifactor. Interacciones, 3(2), 5965. https://doi.org/10.24016/2017.v3n2.51.

Duan, L., \& Zhu, G. (2020). Psychological interventions for people affected by the COVID-19 epidemic. Lancet Psychiatry, 7(4), 300-302. https://doi.org/10.1016/s2215-0366(20)30073-0.

Garcia-Campayo, J., Zamorano, E., Ruiz, M. A., Pardo, A., Perez-Paramo, M., Lopez-Gomez, V., Freire, O., \& Rejas, J. (2010). Cultural adaptation into Spanish of the generalized anxiety disorder-7 (GAD-7) scale as a screening tool. Health and Quality of Life Outcomes, 8, 8. https://doi.org/10.1186/1477-7525-8-8.

Gobierno del Perú. (2020). Sala Situacional COVID-19 Perú. Retrieved from https://covid19.minsa.gob.pe/sala_ situacional.asp. Accessed 3 June 2020.

Gonzalez-Blanch, C., Medrano, L. A., Munoz-Navarro, R., Ruiz-Rodriguez, P., Moriana, J. A., Limonero, J. T., et al. (2018). Factor structure and measurement invariance across various demographic groups and over time for the PHQ-9 in primary care patients in Spain. PLoS One, 13(2), e0193356. https://doi.org/10.1371 /journal.pone.0193356.

Ho, C. S., Chee, C. Y., \& Ho, R. C. (2020). Mental health strategies to combat the psychological impact of COVID-19 beyond paranoia and panic. Annals of the Academy of Medicine, Singapore, 49(1), 1-3.

Holmes, E. A., O'Connor, R. C., Perry, V. H., Tracey, I., Wessely, S., Arseneault, L., Ballard, C., Christensen, H., Cohen Silver, R., Everall, I., Ford, T., John, A., Kabir, T., King, K., Madan, I., Michie, S., Przybylski, A. K., Shafran, R., Sweeney, A., Worthman, C. M., Yardley, L., Cowan, K., Cope, C., Hotopf, M., \& Bullmore, E. (2020). Multidisciplinary research priorities for the COVID-19 pandemic: a call for action for mental health science. Lancet Psychiatry, 7, 547-560. https://doi.org/10.1016/s2215-0366(20)30168-1.

Hu, L.-t., \& Bentler, P. M. (1998). Fit indices in covariance structure modeling: sensitivity to underparameterized model misspecification. Psychological Methods, 3(4), 424-453. https://doi.org/10.1037/1082-989X.3.4.424.

Kelley, K., \& Pornprasertmanit, S. (2016). Confidence intervals for population reliability coefficients: evaluation of methods, recommendations, and software for composite measures. Psychological Methods, 21(1), 69-92. https://doi.org/10.1037/a0040086.

Keum, B. T., Miller, M. J., \& Inkelas, K. K. (2018). Testing the factor structure and measurement invariance of the PHQ-9 across racially diverse U.S. college students. Psychological Assessment. https://doi.org/10.1037 $/$ pas0000550.

Lloret-Segura, S., Ferreres-Traver, A., Hernández-Baeza, A., \& Tomás-Marco, I. (2014). El análisis factorial exploratorio de los ítems: una guía práctica, revisada y actualizada. Anales de psicología, 30(3), 1151-1169.

McDonald, R. P. (1999). Test theory: A unified treatment. New York: Taylor \& Francis Group.

Muñiz, J. (2018). Introducción a la Psicometría: Teoría clásica y TRI. España: Ediciones Pirámide.

Pakpour, A. H., \& Griffiths, M. D. (2020). The fear of COVID-19 and its role in preventive behaviors. Journal of Concurrent Disorders, 2(1), 58-63.

Putnick, D. L., \& Bornstein, M. H. (2016). Measurement invariance conventions and reporting: the state of the art and future directions for psychological research. Developmental Review, 41, 71-90. https://doi.org/10.1016 jj.dr.2016.06.004.

Reznik, A., Gritsenko, V., Konstantinov, V., Khamenka, N., \& Isralowitz, R. (2020). COVID-19 fear in Eastern Europe: validation of the Fear of COVID-19 Scale. International Journal of Mental Health and Addiction, 1-6. https://doi.org/10.1007/s11469-020-00283-3.

Rodriguez, A., Reise, S. P., \& Haviland, M. G. (2016). Evaluating bifactor models: calculating and interpreting statistical indices. Psychological Methods, 21(2), 137-150. https://doi.org/10.1037/met0000045.

Sakib, N., Bhuiyan, A. K. M. I., Hossain, S., Al Mamun, F., Hosen, I., Abdullah, A. H., et al. (2020). Psychometric validation of the Bangla Fear of COVID-19 Scale: confirmatory factor analysis and Rasch analysis. International Journal of Mental Health and Addiction. https://doi.org/10.1007/s11469-020-00289$\mathrm{x}$. 
Saldivia, S., Aslan, J., Cova, F., Vicente, B., Inostroza, C., \& Rincón, P. (2019). Propiedades psicométricas del PHQ-9 (Patient Health Questionnaire) en centros de atención primaria de Chile. Revista Médica de Chile, $147,53-60$.

Satici, B., Gocet-Tekin, E., Deniz, M. E., \& Satici, S. A. (2020). Adaptation of the Fear of COVID-19 Scale: its association with psychological distress and life satisfaction in Turkey. International Journal of Mental Health and Addiction, 1-9. https://doi.org/10.1007/s11469-020-00294-0.

Shigemura, J., Ursano, R. J., Morganstein, J. C., Kurosawa, M., \& Benedek, D. M. (2020). Public responses to the novel 2019 coronavirus $(2019-\mathrm{nCoV})$ in Japan: mental health consequences and target populations. Psychiatry and Clinical Neurosciences, 74, 281-282. https://doi.org/10.1111/pcn.12988.

Soraci, P., Ferrari, A., Abbiati, F. A., Del Fante, E., De Pace, R., Urso, A., \& Griffiths, M. D. (2020). Validation and psychometric evaluation of the Italian version of the Fear of COVID-19 Scale. International Journal of Mental Health and Addiction. https://doi.org/10.1007/s11469-020-00277-1.

Spitzer, R. L., Kroenke, K., Williams, J. B., \& Lowe, B. (2006). A brief measure for assessing generalized anxiety disorder: the GAD-7. Archives of Internal Medicine, 166(10), 1092-1097. https://doi.org/10.1001 /archinte.166.10.1092.

Timmerman, M. E., \& Lorenzo-Seva, U. (2011). Dimensionality assessment of ordered polytomous items with parallel analysis. Psychological Methods, 16(2), 209-220. https://doi.org/10.1037/a0023353.

Tzur Bitan, D., Grossman-Giron, A., Bloch, Y., Mayer, Y., Shiffman, N., \& Mendlovic, S. (2020). Fear of COVID-19 scale: psychometric characteristics, reliability and validity in the Israeli population. Psychiatry Research, 289, 113100. https://doi.org/10.1016/j.psychres.2020.113100.

Velavan, T. P., \& Meyer, C. G. (2020). The COVID-19 epidemic. Tropical Medicine \& International Health, 25(3), 278-280. https://doi.org/10.1111/tmi.13383.

Villarreal-Zegarra, D., \& Bernabe-Ortiz, A. (2020). Association between arterial hypertension and depressive symptoms: results from population-based surveys in Peru. Asia-Pacific Psychiatry, 12(2), e12385. https://doi.org/10.1111/appy.12385.

Villarreal-Zegarra, D., Copez-Lonzoy, A., Bernabe-Ortiz, A., Melendez-Torres, G. J., \& Bazo-Alvarez, J. C. (2019). Valid group comparisons can be made with the Patient Health Questionnaire (PHQ-9): a measurement invariance study across groups by demographic characteristics. PLoS One, 14(9), e0221717. https://doi.org/10.1371/journal.pone.0221717.

Wang, C., Pan, R., Wan, X., Tan, Y., Xu, L., McIntyre, R. S., Choo, F. N., Tran, B., Ho, R., Sharma, V. K., \& Ho, C. (2020). A longitudinal study on the mental health of general population during the COVID-19 epidemic in China. Brain, Behavior, and Immunity. https://doi.org/10.1016/j.bbi.2020.04.028.

Weiss, D. S., \& Marmar, C. R. (1997). The Impact of Event Scale-Revised. In J. P. Wilson \& T. M. Keane (Eds.), Assessing psychological trauma and PTSD (pp. 399-411). New York: Guilford Press.

Widaman, K. F., \& Reise, S. P. (1997). Exploring the measurement invariance of psychological instruments: applications in the substance use domain. The science of prevention: Methodological advances from alcohol and substance abuse research, 281-324.

Publisher's Note Springer Nature remains neutral with regard to jurisdictional claims in published maps and institutional affiliations.

\section{Affiliations}

\section{Jeff Huarcaya-Victoria ${ }^{1} \cdot$ David Villarreal-Zegarra ${ }^{2,3,4} \cdot$ Angela Podestà $^{5} \cdot$ María $^{2}$ Alejandra Luna-Cuadros ${ }^{6}$}

1 Facultad de Medicina, Centro de Investigación en Salud Pública, Universidad de San Martín de Porres, Lima, Peru

2 Instituto Peruano de Orientación Psicológica, Lima, Peru

3 CRONICAS Center of Excellence in Chronic Diseases, Universidad Peruana Cayetano Heredia, Lima, Peru

4 Instituto de Investigación, Universidad Católica los Ángeles de Chimbote, Chimbote, Peru

5 Hospital Nacional Guillermo Almenara Irigoyen, EsSalud. Departamento de Psiquiatría, Unidad de Psiquiatría de Enlace, Lima, Peru

6 Neuromodulation Center and Center for Clinical Research Learning, Spaulding Rehabilitation Hospital and Massachusetts General Hospital, Charlestown, MA, USA 